\title{
Double-Stranded RNA Is a Novel Molecular Target in Osteomyelitis Pathogenesis
}

\section{A Translational Avian Model for Human Bacterial Chondronecrosis with Osteomyelitis}

\begin{abstract}
Elizabeth Greene, ${ }^{*}$ Joshua Flees, ${ }^{*}$ Ahmed Dhamad, ${ }^{*}$ Adnan Alrubaye, ${ }^{\dagger}$ Stephen Hennigan,${ }^{\ddagger}$ Jason Pleimann,${ }^{\ddagger}$ Mark Smeltzer, Sue Murray, ${ }^{\top}$ Jennifer Kugel, James Goodrich, Avril Robertson, ${ }^{* *}$ Robert Wideman, ${ }^{*}$ Douglas Rhoads, ${ }^{* \dagger}$ and Sami Dridi ${ }^{* \dagger}$

From the Center of Excellence for Poultry Science* and the Cell and Molecular Biology Program, ${ }^{\dagger}$ University of Arkansas, Fayetteville, Arkansas; the Washington Regional Medical Center ${ }^{\ddagger}$ Fayetteville, Arkansas; the Department of Microbiology and Immunology, ${ }^{\S}$ University of Arkansas for Medical Sciences, Little Rock, Arkansas; the Antisense Drug Discovery, "IONIS Pharmaceuticals, Carlsbad, California; the Department of Chemistry and Biochemistry," University of Colorado Boulder, Boulder, Colorado; and the Institute for Molecular Bioscience, ** The University of Queensland, Brisbane, Queensland, Australia
\end{abstract}

Accepted for publication June 19, 2019.

Address correspondence to Sami Dridi, Ph.D., Center of Excellence for Poultry Science, University of Arkansas, 1260 W Maple St., Fayetteville, AR 72701. E-mail: dridi@ uark.edu.

\begin{abstract}
Osteomyelitis remains a serious inflammatory bone disease that affects millions of individuals worldwide and for which there is no effective treatment. Despite scientific evidence that Staphylococcus bacteria are the most common causative species for human bacterial chondronecrosis with osteomyelitis (BCO), much remains to be understood about the underlying virulence mechanisms. Herein, we show increased levels of double-stranded RNA (dsRNA) in infected bone in a Staphylococcus-induced chicken BC0 model and in human osteomyelitis samples. Administration of synthetic [poly(I:C)] or genetic (Alu) dsRNA induces human osteoblast cell death. Similarly, infection with Staphylococcus isolated from chicken BCO induces dsRNA accumulation and cell death in human osteoblast cell cultures. Both dsRNA administration and Staphylococcus infection activate NACHT, LRR and PYD domains-containing protein (NLRP) 3 inflammasome and increase IL18 and IL1B gene expression in human osteoblasts. Pharmacologic inhibition with Ac-YVAD-cmk of caspase 1, a critical component of the NLRP3 inflammasome, prevents DICER1 dysregulation - and dsRNA-induced osteoblast cell death. NLRP3 inflammasome and its components are also activated in bone from BCO chickens and humans with osteomyelitis, compared with their healthy counterparts. These findings provide a rationale for the use of chicken BCO as a human-relevant spontaneous animal model for osteomyelitis and identify dsRNA as a new treatment target for this debilitating bone pathogenesis. (Am J Pathol 2019, 189: 2077-2089; https://doi.org/ 10.1016/j.ajpath.2019.06.013)
\end{abstract}

Osteomyelitis is an exceedingly common severe inflammatory bone disease that is caused by an infecting microorganism and leads to progressive bone attrition. ${ }^{1}$ The causative agents of osteomyelitis are variable, depending on the type of osteomyelitis (acute or chronic), route of inoculation (hematogenous spread, direct inoculation, or contiguous focus of infection), and age of patient. ${ }^{2}$ Opportunistic Staphylococcus species, particularly Staphylococcus aureus and Staphylococcus epidermidis, are the most predominant isolates. Staphylococcal infections can occur in any bone in the skeleton and strike any age group, and they are becoming an increasing global concern. Infections are generally associated with formation of biofilms and complicated by development of drug-resistant variants, including methicillin- and vancomycin-resistant $S$. aureus. ${ }^{3-6}$ In immunocompromised patients with diabetes mellitus, Staphylococcus infections are

Supported by Arkansas Agricultural Experiment Station grant FY2017 (S.D.).

Disclosures: S.M. is an employee of IONIS Pharmaceuticals. 
life threatening because their metastatic complications can lead to mortality. ${ }^{7-9}$

Although it has well been established that staphylococcal infection can lead to bone cell death via apoptosis and necrosis, the underlying molecular mechanisms by which this occurs are not completely defined. ${ }^{10}$ Without a basic understanding of the pathology of this debilitating disease, the identification and development of effective therapeutic strategies will likely remain limited.

The status quo pertaining to definition of the molecular mechanisms of osteomyelitis is to focus on the pathogenesis of Staphylococcus injection in combination with sclerosing agents, foreign bodies, additional tissue damage, or host genetic mutation. ${ }^{11-16}$ Although these animal models have provided valuable mechanistic insights, they are also limited because they can only capture features of acute or chronic osteomyelitis. Herein, we used a human-relevant avian model that mimics osteomyelitis in growing children and avascular femoral head necrosis in adults. The model does not rely on foreign bodies and bacterial inoculation. ${ }^{17}$ Wideman and coworkers ${ }^{17,18}$ have recently developed a wire flooring model for reliably triggering high incidence of bacterial chondronecrosis with osteomyelitis (BCO). The sustained instability of the footing on wire flooring exposes susceptible joints to persistent torque and shear stress that, in turn, results in microtrauma and osteochondrosis of the epiphyseal-physeal cartilage, accompanied by mechanical truncation and thrombotic occlusion of metaphyseal blood vessels and hematogenous colonization by translocated Staphylococcus bacteria. ${ }^{18}$

Recently, Kanneganti and colleagues ${ }^{19}$ have uncovered a redundant role of NACHT, LRR and PYD domains-containing protein (NLRP)3 inflammasome and caspase 8 in promoting IL-1 $\beta$-mediated osteomyelitis in a Pstpip $2^{\mathrm{cmo}}$ mouse, a model for chronic multifocal osteomyelitis. NLRP3 inflammasome activation and IL- $1 \beta$ maturation are targeted by endogenous cytotoxic double-stranded RNA accumulation induced by DICER1 dysregulation in age-related macular degeneration $^{20,21}$; we, therefore, hypothesized that doublestranded RNA (dsRNA) accumulation may mediate the effect of Staphylococcus infection on bone cell degeneration.

It was first demonstrated that DICER 1 expression is down-regulated, whereas dsRNA levels were increased in bone from BCO chickens and humans with osteomyelitis compared with their healthy counterparts. DICER 1 knockdown or exposure to chicken BCO-Staphylococcus isolates induce dsRNA accumulation and cell death of human osteoblasts in culture. Similarly, administration of dsRNA reduces human osteoblast cell viability. All these treatments activate NLRP3 inflammasome, and pharmacologic inhibition of NLRP3 components rescue human osteoblast cell viability. Furthermore, NLRP3 inflammasome is also activated in bone from BCO chickens and humans with osteomyelitis compared with their healthy counterparts. Together, these findings reveal a previously unrecognized function of dsRNA in osteomyelitis pathogenesis and provide a potential therapeutic approach in osteomyelitis.

\section{Materials and Methods}

\section{BCO Animal Model}

All animal experiments were approved by the University of Arkansas (Fayetteville, AR) Animal Care and Use Committee (protocol number 15043) and were in accordance with recommendations in NIH's Guide for the Care and Use of Laboratory Animals. ${ }^{22}$ The BCO chicken model and its healthy counterparts were previously described. ${ }^{17,18}$ The experiment was conducted in the Poultry Environmental Research Laboratory at the University of Arkansas Poultry Research Farm. Animals had ad libitum access to fresh water and feed (3.9 Mcal metabolizable energy $\mathrm{kg}^{-1}$ and $180 \mathrm{~g}$ crude protein $\mathrm{kg}^{-1}$ ). The ambient temperature was reduced gradually from $32^{\circ} \mathrm{C}$ to $25^{\circ} \mathrm{C}$ at 21 days of age. A relative humidity of approximately $20 \%$ and 23 hours light/ 1 hour dark cycles were also maintained until the end of the experiment. At the end of the experiment (56 days), animals were weighed, humanely euthanized, and necropsied to assess subclinical lesion incidences in the proximal heads of the femora and tibiae. A portion of bone was snap frozen in liquid nitrogen and stored at $-80^{\circ} \mathrm{C}$ for later analysis.

\section{Human Bone Tissues}

Donor bone tissues from age-matched patients with osteomyelitis or patients without osteomyelitis were obtained from the Washington Regional Medical Center (Fayetteville, AR) on securing informed consent from donors. The study followed the guidelines of the Declaration of Helsinki, and these deidentified specimens were collected under institutional review board-approved protocols (numbers 15-12-421 and U-107).

\section{Cell Culture}

Human fetal osteoblast (hFOB) 1.19 cells (CRL-11372; ATCC, Manassas, VA) were cultured in a 1:1 mixture of Ham's F12 medium/Dulbecco's modified Eagle's medium, with $0.3 \mathrm{mg} / \mathrm{mL} \mathrm{G} 418$ and $10 \%$ fetal bovine serum. MG-63 cells (CRL-1427; ATCC) were cultured in Eagle's minimum essential medium supplemented with $10 \%$ heatinactivated fetal bovine serum and $1 \%$ penicillin/streptomycin. Ob-6 cells (a generous gift from Dr. Charles O'Brien, University of Arkansas for Medical Sciences, Little Rock, AR) were cultured in minimal essential medium- $\alpha$, supplemented with $10 \%$ fetal bovine serum and $1 \%$ penicillin/streptomycin. All cells were grown in a humidified atmosphere of $5 \% \mathrm{CO}_{2}$ and $95 \%$ air, with hFOB at $34^{\circ} \mathrm{C}$ and MG-63 and $\mathrm{Ob}-6$ at $37^{\circ} \mathrm{C}$.

\section{Transient Plasmid Transfection}

Human osteoblast cells were pretreated with caspase 1 inhibitor, Ac-YVAD-cmk (100 $\mu \mathrm{mol} / \mathrm{L}$; InvivoGen, San Diego, CA) 1 hour before transfection. At $50 \%$ confluence, 
cells were transfected with siDICER1 or scrambled siRNA (Thermo Fisher Scientific, Waltham, MA), pAlu, ${ }^{23}$ plasmid NLRP3 (a generous gift from Drs. Ronald N. Germain and Naeha Subramanian, Institute for Systems Biology, Seattle, WA $),{ }^{24}$ poly(I:C) $(500 \mathrm{ng} / \mathrm{mL} ; \mathrm{R} \& \mathrm{D}$ Systems, Minneapolis, $\mathrm{MN}$ ), or their backbones pUC18 and pcDNA3.1(+) for Alu and NLRP3, respectively. A pool of two sense and antisense siDICER1 (23755 sense: CAGCAUACUUUAUCGCCUTT; 23755 antisense: AAGGCGAUAAAGUAUGCUGGG; 23756 sense: GGCUUAU AUCAGUAGCAAUTT; and 23756 antisense: AUUGCUACUGAUAUAAGCCAG) and scrambled Silencer Select Negative Control (Thermo Fisher Scientific, Grand Island, NY) were administered using Lipofectamine RNAiMax transfection reagent (Thermo Fisher Scientific, Grand Island, NY); however the other plasmids were transfected using Lipofectamine 2000 (Thermo Fisher Scientific, Waltham, MA), according to the manufacturer's instructions. Six hours after transfection, complete medium was added, and cells were maintained for an additional 24 hours and processed for gene expression, immunoblotting, immunofluorescence staining, or cell viability.

\section{Bacterial Infection}

Staphylococcus bacteria (S. aureus strain 1302, Staphylococcus agnetis strain 908) were isolated from the bone of BCO model, ${ }^{25}$ and Staphylococcus hyicus strain 1401 was isolated from bovine mastitis. Staphylococcus bacteria were grown overnight at $37^{\circ} \mathrm{C}$ in Luria broth. Cultures were diluted in phosphate-buffered saline, and absorbance was measured at $650 \mathrm{~nm}$ to determine cell density. Bacteria were added to cell cultures at a multiplicity of infection of 50:1 in antibiotic-free media and allowed to attach for 1 hour. Cells were then washed $3 \times$ in phosphate-buffered saline, complete medium was added, and cells were maintained for additional 24 hours and processed for gene expression, immunoblotting, immunofluorescence staining, or cell viability.

\section{Cell Viability}

Cell viability was performed, as previously described. ${ }^{23}$ Briefly, hFOB 1.19, MG-63, or Ob-6 cells were seeded in a 96-well plate at $1 \times 10^{4}$ cells per well and transfected as described above. CellTiter 96 AQueous One Solution Cell Proliferation Assay (Promega, Madison, WI) was used, according to manufacturer's recommendations, and results were obtained using a Synergy HT multimode microplate reader (BioTek, Winooski, VT). All sample readings were corrected for background, and results were reported relative to control.

\section{Real-Time Quantitative PCR}

Total RNA was isolated from bone samples, according to the protocol of Carter et $\mathrm{al}^{26}{ }^{26}$ and from cells using Trizol reagent (Life Technologies, Carlsbad, CA), according to the manufacturer's instructions. After treatment with RNasefree DNase, RNA integrity and quality were assessed via $1 \%$ agarose gel electrophoresis; and the concentrations were determined by using the Take3 microvolume plate and Synergy HT multimode microplate reader. Total RNA (1 $\mu \mathrm{g}$ ) was reverse transcribed using qScript cDNA SuperMix (Quanta Biosciences, Gaithersburg, MD) and amplified by real-time quantitative PCR (7500 Real Time System; Applied Biosystems, Foster City, CA) with Power SYBR Green Master Mix (Life Technologies). Oligonucleotide primers specific for chicken DICER1 (forward, 5'TTTAAACACTGGCTCAGGGAAGA-3'; and reverse, $5^{\prime}$ AAATCCCCCCTGATCTGATAGG- $3^{\prime}$ ), $N L R P 3$ (forward, 5'-GTTGGGCAGTTTCACAGGAATAG- ${ }^{\prime}$; and reverse, 5'-GCCGCCTGGTCATACAGTGT-3'), CASP1 (forward, 5'-TGCGGGACCAAGAGTAATGG-3'; and reverse, 5'AATTCTCGTAGATGGTGTTGAAGGA-3'), CASP3 (forward, 5'-GGAACACGCCAGGAAACTTG- $3^{\prime}$; and reverse, 5'-TCTGCCACTCTGCGATTTACA-3'), ILIB (forward, 5'-CGAGGAGCAGGGACTTTGC- $3^{\prime}$; and reverse, 5'GAAGGTGACGGGCTCAAAAA-3'), IL18 (forward, 5'TGCAGCTCCAAGGCTTTTAAG-3'; and reverse, $5^{\prime}$ CTCAAAGGCCAAGAACATTCCT- $3^{\prime}$ ), $r 18 S$ as housekeeping gene (forward, 5'-TCCCCTCCCGTTACTTGGAT-3'; and reverse, 5'-GCGCTCGTCGGCATGTA-3'), human DICER1 (forward, 5'-CCCGGCTGAGAGAACTTACG-3'; and reverse, 5'-TGTAACTTCGACCAACACCTTTAAAT-3'), NLRP3 (forward, $5^{\prime}$ GCACCTGTTGTGCAATCTGAA-3'; and reverse, 5'TCCTGACAACATGCTGATGTGA-3'), ASC (forward, 5' GCCAGGCCTGCACTTTATAGA-3'; and reverse, $5^{\prime}$ GTTTGTGACCCTCGCGATAAG-3'), CASP1 (forward, 5'- ATACCAAGAACTGCCCAAGTTTG-3'; and reverse, 5'-GGCAGGCCTGGATGATGA-3'), CASP3 (forward, 5'GCCTACAGCCCATTTCTCCAT-3'; and reverse, $5^{\prime}$ GCGCCCTGGCAGCAT-3'), ILIB (forward, 5'-TCAGCCAATCTTCATTGCTCAA- $3^{\prime} ;$ and reverse, $5^{\prime}$ TGGCGAGCTCAGGTACTTCTG-3'), IL18 (forward, 5' ATCACTTGCACTCCGGAGGTA-3'; and reverse, 5'AGAGCGCAATGGTGCAATC- $3^{\prime}$ ), Alu (forward, 5'CCATCCTGGCTAACACAGTGAA- ${ }^{\prime}$; and reverse, $5^{\prime}$ CCACTCCCGGCTAATTTTTTG- $3^{\prime}$ ), and $r 18 S$ (forward, 5'-CGAACCTCTGCCCTATCAACTT-3'; and reverse, 5'ACCCGTGGTCACCATGGTA- $3^{\prime}$ ) were used. The realtime quantitative PCR cycling conditions were $50^{\circ} \mathrm{C}$ for 2 minutes, $95^{\circ} \mathrm{C}$ for 10 minutes, followed by 40 cycles of a two-step amplification program $\left(95^{\circ} \mathrm{C}\right.$ for 15 seconds and $58^{\circ} \mathrm{C}$ for 1 minute). At the end of the amplification, melting curve analysis was applied using the dissociation protocol from the sequence detection system to exclude contamination with non-specific PCR products. The PCR products were also confirmed by agarose gel and showed only one specific band of the predicted size. For negative controls, no reverse transcription products were used as templates in the real-time quantitative PCR and verified by the absence of gel-detected bands. Relative expression of target genes was 
determined using the $2^{-\Delta \Delta C T}$ method, ${ }^{27}$ and healthy subjects and untreated, scrambled siRNA, or plasmid null transfected cells were used as calibrators.

\section{Western Blot Analysis}

Cells were washed with phosphate-buffered saline and homogenized in lysis buffer $(10 \mathrm{mmol} / \mathrm{L}$ Tris base, $\mathrm{pH} 7.4$; $150 \mathrm{mmol} / \mathrm{L} \mathrm{NaCl} ; 1 \mathrm{mmol} / \mathrm{L}$ EDTA; $1 \mathrm{mmol} / \mathrm{L}$ EGTA; $0.1 \%$ Triton X-100; $0.5 \%$ Nonidet P-40; and protease and phosphatase inhibitors). For the chicken and human bone samples, a piece of bone was homogenized in lysis buffer, using the Bullet Blender Storm (NextAdvance, Averill Park, NY) and stainless steel beads. Protein concentrations were determined using a Bradford assay kit (Bio-Rad, Hercules, CA) and a Synergy HT multimode microplate reader. Proteins were run on $4 \%$ to $12 \%$ gradient Bis-Tris gels (Life Technologies) and transferred to polyvinylidene difluoride membranes. The membranes were blocked with $5 \%$ nonfat milk in Tris-buffered saline (TBS) and Tween 20 for 1 hour at room temperature and then incubated with primary antibodies (dilution 1:500 to $1: 1000$ ) overnight at $4^{\circ} \mathrm{C}$. Secondary antibodies (dilution 1:5000) were diluted in $5 \%$ nonfat milk in TBS and Tween 20, and membranes were incubated at room temperature for 1 hour. The signal was visualized by chemiluminescence (ECL Plus; GE Healthcare, Pittsburg, PA) and captured by the FluorChem M MultiFluor System (ProteinSimple, San Jose, CA). Densitometric analysis of each blot was performed using AlphaView SA version 3.4.0 (ProteinSimple). Primary antibodies used were rabbit anti-DICER1, rabbit anti-NLRP3, and goat anti-caspase 1 (Santa Cruz Biotechnology, Dallas, TX). Protein loading was assessed by immunoblotting using rabbit anti-glyceraldehyde-3-phosphate dehydrogenase (Santa Cruz Biotechnology, Dallas, TX) or rabbit anti-actin antibodies (Cell Signaling Technology, Danvers, MA).

\section{Immunodetection of dsRNA with Enzyme-Linked Immunosorbent Assay}

Cells or bone samples were homogenized in Nonidet P-40 lysis buffer containing RNase inhibitors (Protecor RNase Inhibitor; Roche Diagnostics, Mannheim, Germany), proteinase (cOmplete; Roche Diagnostics), and phophatase inhibitors (PhosSTOP EASYpack; Roche Diagnostics); and diluted 1:4 (chicken) or 1:10 (human) with blocking buffer (Superblock Blocking Buffer; Thermo Fisher Scientific); and then incubated at $4^{\circ} \mathrm{C}$ overnight in a protein $\mathrm{A}$ microplate coated with J2 antibody ( $1 \mu \mathrm{g} / \mathrm{mL}$; SCICONS, Budapest, Hungary). The plate was washed three times with TBS with $0.05 \%$ Tween-20, and then K2 antibody (dilution 1:4; SCICONS) was added for 1 hour at room temperature. The plate was washed $3 \times$ with TBS and Tween 20 and incubated with biotin-conjugated donkey anti-mouse IgM secondary antibody (dilution 1:1000; Jackson ImmunoResearch Laboratories Inc., West Grove, PA) for 1 hour at room temperature.
Streptavidin $(0.5 \mu \mathrm{g} / \mathrm{mL}$; Thermo Fisher Scientific) was added for 1 hour at room temperature, followed by washing $3 \times$ in TBS and Tween 20. 3,3',5,5'-Tetramethylbenzidine substrate solution (Thermo Fisher Scientific) was added for 30 minutes, and the reaction was stopped and absorbance was read at $450 \mathrm{~nm}$ using a Synergy HT multimode microplate reader. A standard curve was generated using serial dilutions of poly(I:C) (low molecular weight; InvivoGen) from 3.1 to $2000 \mathrm{pg} / \mathrm{mL}$ in blocking buffer.

\section{Immunofluorescence}

Human osteoblasts were grown to approximately $70 \%$ confluence in Nunc Lab-Tek II chamber slides (Thermo Fisher Scientific), and immunofluorescence staining was performed, as previously described. ${ }^{23}$ In brief, after treatment (bacterial infection or plasmid transfection), cells were fixed with methanol for 10 minutes at $-20^{\circ} \mathrm{C}$ and then permeabilized with Triton-X 100. Cells were blocked with serum-free protein block (Dako, Carpinteria, CA) for 1 hour at room temperature and then incubated with primary antibodies (dilution 1:200; in Antibody Diluent; Dako) overnight at $4^{\circ} \mathrm{C}$. Signal was visualized with DyLight $488-$ or DyLight 594-conjugated secondary antibodies (Thermo Fisher Scientific). Slides were coverslipped with Vectashield with DAPI (Vector Laboratories, Burlingame, CA), and images were obtained using Zeiss Imager M2 and AxioVision software version LE2019 (Carl Zeiss Microscopy, Oberkochen, Germany). In addition to antibodies used in Western blot analysis, mouse anti-dsRNA antibody (SCICONS) and rabbit anti-nucleolysin TIA-1 isoform $\mathrm{p} 40$ (TIA-1) (Abcam, Cambridge, MA) were used.

\section{LC-MS/MS Analysis}

Chicken tibia samples were homogenized in lysis buffer (10 mmol/L Tris base, $\mathrm{pH} 7.4 ; 150 \mathrm{mmol} / \mathrm{L} \mathrm{NaCl} ; 1 \mathrm{mmol} /$ L EDTA; 1 mmol/L EGTA; 0.1\% Triton X-100; 0.5\% Nonidet P-40; and protease and phosphatase inhibitors). Proteins $(100 \mu \mathrm{g})$ were resolved by $4 \%$ to $12 \%$ Novex BisTris gels (Thermo Fisher Scientific, Waltham, MA). The gel was then stained with Coomassie Brilliant Blue dye. Gel portions of each sample were excised and chopped into small pieces $\left(<1 \mathrm{~mm}^{2}\right)$ and washed twice with 25 $\mathrm{mmol} / \mathrm{L} \mathrm{NH}_{4} \mathrm{HCO}_{3}$. The gel pieces were destained with 25 $\mathrm{mmol} / \mathrm{L} \mathrm{NH}_{4} \mathrm{HCO}_{3} / 50 \%$ acetonitrile and dried with $100 \%$ acetonitrile. Proteins were then reduced using $10 \mathrm{mmol} / \mathrm{L}$ dithiothreitol in $25 \mathrm{mmol} / \mathrm{L} \mathrm{NH}_{4} \mathrm{CO}_{3}$ at $56^{\circ} \mathrm{C}$ for 1 hour. Subsequently, alkylation was conducted using $55 \mathrm{mmol} / \mathrm{L}$ iodoacetamide in $25 \mathrm{mmol} / \mathrm{L} \mathrm{NH}_{4} \mathrm{CO}_{3}$, protected from light. The gel pieces were then washed with $25 \mathrm{mmol} / \mathrm{L}$ $\mathrm{NH}_{4} \mathrm{HCO}_{3}$, dehydrated with $25 \mathrm{mmol} / \mathrm{L} \mathrm{NH}_{4} \mathrm{HCO}_{3} / 50 \%$ acetonitrile, and completely dried via SpeedVac (Eppendorf, Hamburg, Germany). Mass spectrometry grade Trypsin Gold $\left(12.5 \mathrm{ng} / \mu \mathrm{L}\right.$ in $25 \mathrm{mmol} / \mathrm{L} \mathrm{NH}_{4} \mathrm{HCO}_{3}$; Promega) was added to dried gels and incubated overnight at $37^{\circ} \mathrm{C}$. Peptides were extracted by $50 \%$ acetonitrile $/ 5 \%$ 
formic acid. The tryptic digests were desalted using Pierce C18 spin columns (Thermo Fisher Scientific, Waltham, MA) before liquid chromatography-tandem mass spectrometry (LC-MS/MS). LC-MS/MS samples were analyzed using Mascot version 2.2.1 (Matrix Science, London, UK). MS/MS-based peptide and protein sequence identification was validated using Scaffold version 4.8.3 (Proteome Software Inc., Portland, OR) and was accepted by the Scaffold Local false discovery rate algorithm when the probability was $>95 \% .^{25}$

\section{Statistical Analysis}

Results are expressed as means \pm SEM, with $P<0.05$ considered statistically significant. Differences between groups were analyzed by one-way analysis of variance or $t$ test, as appropriate. If analysis of variance revealed significant effects, the means were compared by the post hoc Student-Newman-Keuls multiple-comparison test using GraphPad Prism version 7.03 (GraphPad Software, Inc., La Jolla, CA).

\section{Chicken}
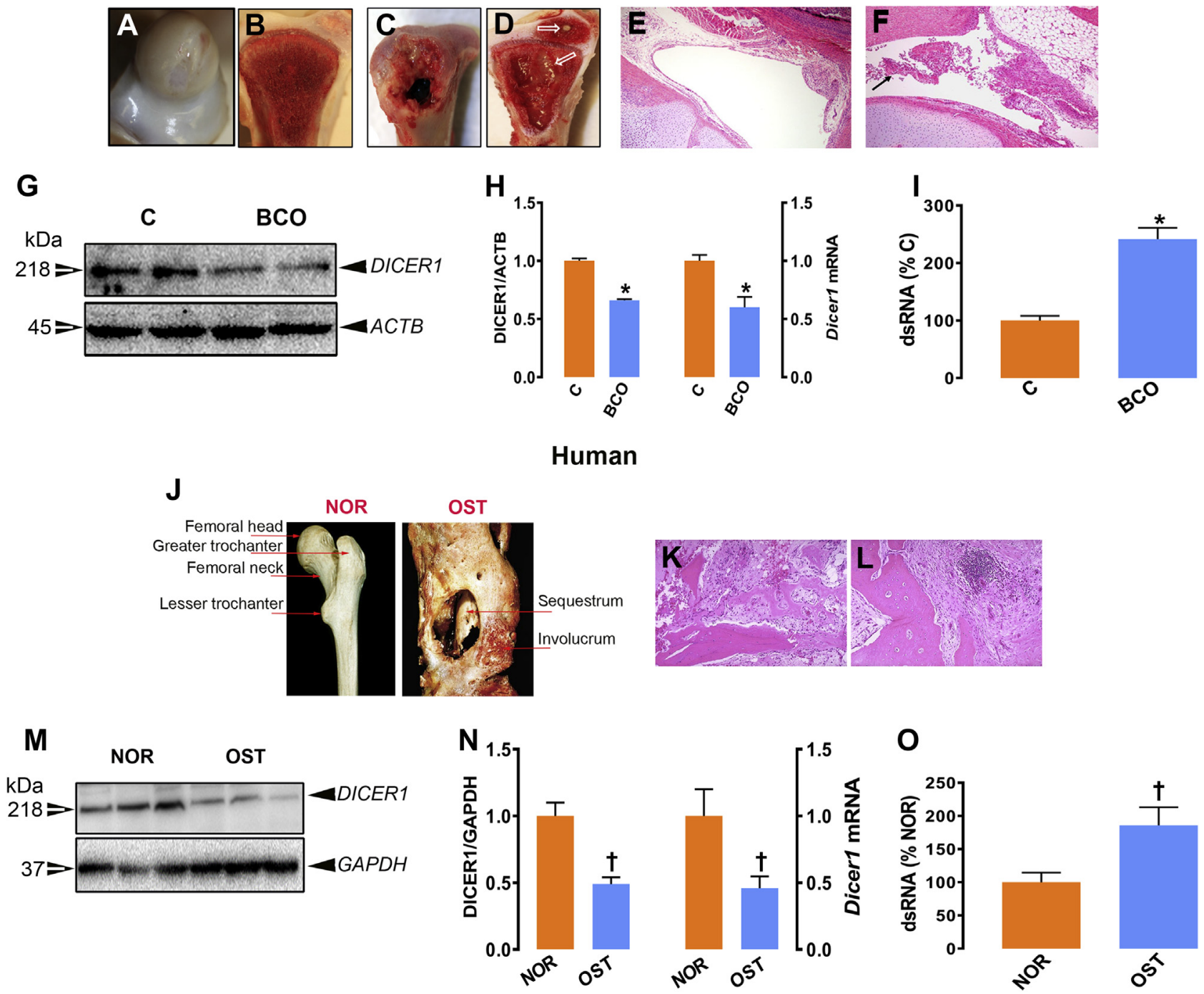

Figure 1 Dicer dysregulation and dsRNA accumulation in the proximal femur and tibia of bacterial chondronecrosis with osteomyelitis (BCO) chicken and human bone with osteomyelitis. A-D and J: Macroscopic analysis shows normal and abnormal bone with sequestrum and involucrum (open arrows; D) in chicken [normal femur (A), normal tibia (B), femoral head necrosis (C), and tibial head necrosis (D)] and human [normal femur (NOR) and femur with osteomyelitis (OST); J]. E, F, K, and L: Histologic analysis illustrates a chronic inflammation along with fibrinoheterophilic synovitis with exudate in chicken (arrow; F) and human femur (L) compared with healthy bone [chicken (E) and human (K)]. E and F: Adapted from Wijesurendra et al, ${ }^{28}$ with permission from Taylor \& Francis. G, H, M, and N: Decreased expression of DICER1 mRNA and protein in chicken BCO tibia (G and $\mathbf{H}$ ) and human bone with osteomyelitis (M and $\mathbf{N}$ ), assessed by quantitative PCR and Western blot analysis, respectively. I and $\mathbf{0}$ : Accumulation of dsRNA levels in chicken BCO tibia (I) and human bone with osteomyelitis (0), determined by enzyme-linked immunosorbent assay. Data are expressed as means $\pm \mathrm{SEM}(\mathbf{H}, \mathbf{I}, \mathbf{N}$, and $\mathbf{0})$. ${ }^{*} P<0.05$ versus control ( $t$-test); ${ }^{\dagger} P<0.05$ versus normal femur (t-test). Original magnification, $\times 40(\mathbf{E}, \mathbf{F}, \mathbf{K}$, and $\mathbf{L})$. ACTB, actin; $C$, control; GAPDH, glyceraldehyde-3-phosphate dehydrogenase. 


\section{Results}

DICER1 Dysregulation and dsRNA Accumulation in Tibia of BCO Chicken and Human Bone with Osteomyelitis

Similar clinical and macroscopic hallmarks of BCO and osteomyelitis are the presence of dead bone (sequestrum), involucrum, and necrosis with bone loss (Figure 1, A-D and J). At the histopathologic level, both BCO and osteomyelitis encompass the full scope of inflammatory infiltrates, ranging from fibrin to marrow fibrosis with scattered mononuclear cells (Figure 1, E, F, K, and L). ${ }^{28}$

In search of potential molecular signatures, LC-MS/MS was performed on protein isolated from the proximal end of the tibia from $\mathrm{BCO}$ and healthy chickens. Among several differentially expressed proteins, DICER1 expression was down-regulated in BCO compared with healthy chickens. In agreement with LC-MS/MS data, DICERI mRNA abundance and protein levels were significantly down-regulated in BCO tibia compared with their healthy counterparts, as assessed by real-time quantitative PCR and Western blot analyses, respectively (Figure 1, G and H). Similarly, DICER1 expression at mRNA and protein levels was down-regulated in human bone with osteomyelitis compared with healthy subjects (Figure 1, M and N).

As endogenous dsRNAs are substrates for DICER $1,{ }^{20}$ an enzyme-linked immunosorbent assay was developed using a specific antibody for dsRNA; and significantly higher levels of dsRNA were detected in chicken BCO tibia and human bone with osteomyelitis compared with their healthy counterparts (Figure 1, I and O).

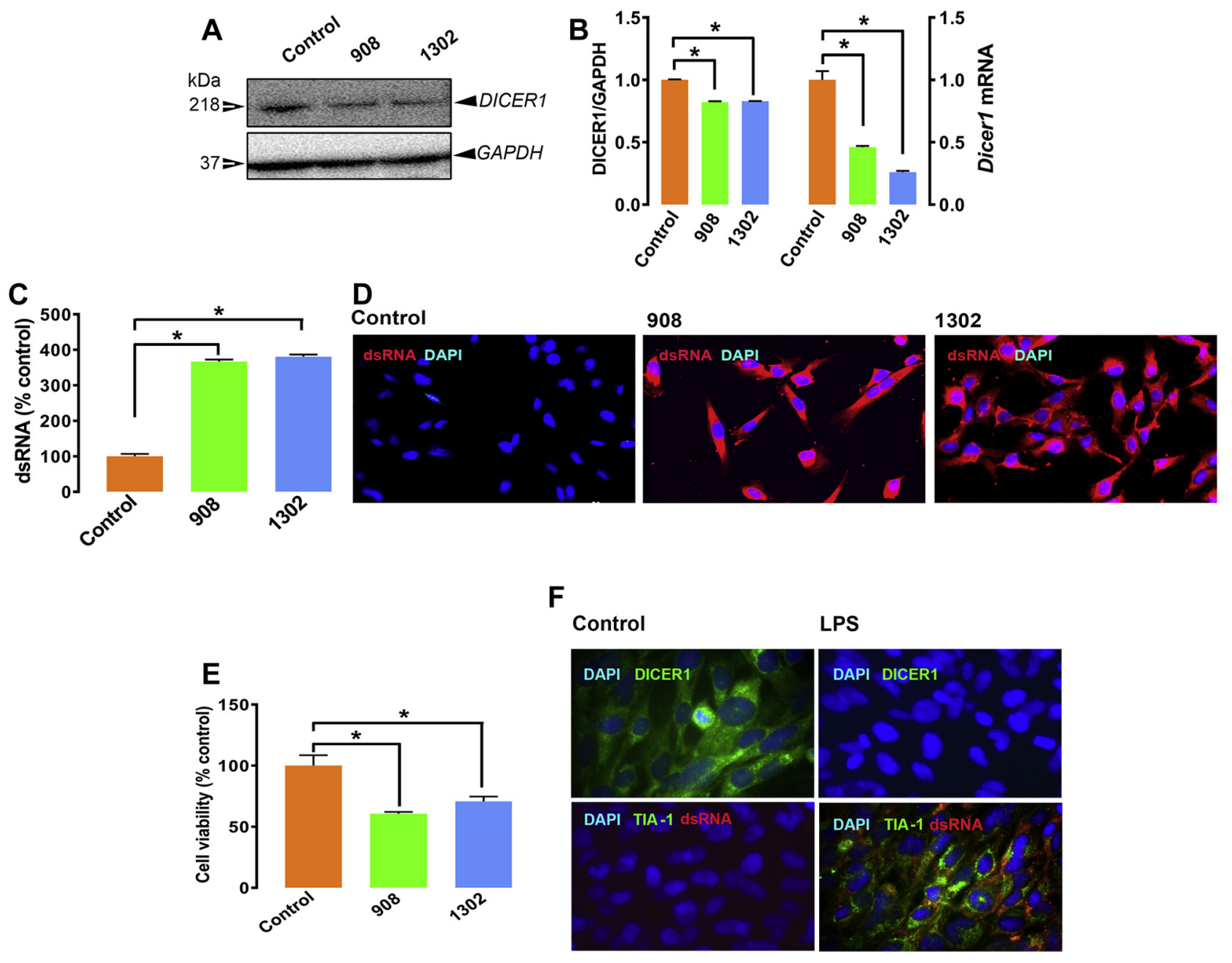

Figure 2 Staphylococcus infection decreases DICER1 expression, increases dsRNA levels, and induces osteoblast cell death. A-E: Infection with chicken bacterial chondronecrosis with osteomyelitis-Staphylococcus isolates (908 and 1302) at a multiplicity of infection of 50:1 down-regulates DICER1 mRNA and protein levels (A and $\mathbf{B})$, induces dsRNA accumulation (C and $\mathbf{D})$, and reduces human fetal osteoblast cell viability (E) compared with the control. F: Lipopolysaccharide treatment $(50 \mu \mathrm{mol} / \mathrm{L})$ decreases DICER1 expression and induces dsRNA accumulation, as assessed by immunofluorescence staining. Images are representative of three to four independent experiments. Data are expressed as means \pm SEM (B, C, and E). ${ }^{*} P 0.05$ (analysis of variance and post hoc Student-Newman-Keuls multiple-comparison test). Original magnification, $\times 40$ (D and F). GAPDH, glyceraldehyde-3-phosphate dehydrogenase. 


\section{Staphylococcus Infection or DICER1 Knockdown}

Induces dsRNA Accumulation and Reduces Human

Osteoblast Cell Viability

Infection of hFOB 1.19 and MG-63 with two Staphylococcus species (S. aureus 1302 and S. agnetis 908), isolated from $\mathrm{BCO}$ chickens, significantly downregulates the expression of DICER1 at mRNA and protein levels (Figure 2, A and B, and Supplemental Figure S1); increases dsRNA levels, as assessed by enzyme-linked immunosorbent assay and immunofluorescence analysis (Figure 2, C and D, and Supplemental Figure $\mathrm{S} 1$ ); and reduces cell viability (Figure $2 \mathrm{E}$ and Supplemental Figure S1). However, infection with an $S$. hyicus strain, isolated from bovine mastitis, does not affect either DICER1/dsRNA expression or hFOB cell viability (data not shown). As a positive control and in agreement with a previous study in HCT116 cells, ${ }^{29}$ lipopolysaccharide treatment reduces DICER1 expression in hFOB cells (Figure 2F). This dysregulation of DICER 1 is accompanied by dsRNA accumulation, which seems to be colocalized with the stress granule marker TIA-1 (Figure 2F).

To assess whether dsRNA accumulation was a consequence of reduced DICER1 levels, siRNA-mediated DICER1 knockdown was used (Figure 3, A-C, and Supplemental Figure S1); and DICER1 deficit was found to increase dsRNA levels (Figure 3, C and D) and reduce hFOB and MG-63 cell viability (Figure 3D and Supplemental Figure S1). DICER1 knockdown also induces the expression of Alu repeat element (Figure 3E), and Alu repeats have been previously shown to form long dsRNA that are substrates for DICER $1 .{ }^{20}$ Overexpression of Alu or administration of dsRNA analogue poly(I:C) reduces $\mathrm{hFOB}$ and MG-63 cell viability (Figure 3, F-H, and Supplemental Figure $\mathrm{S} 1$ ).
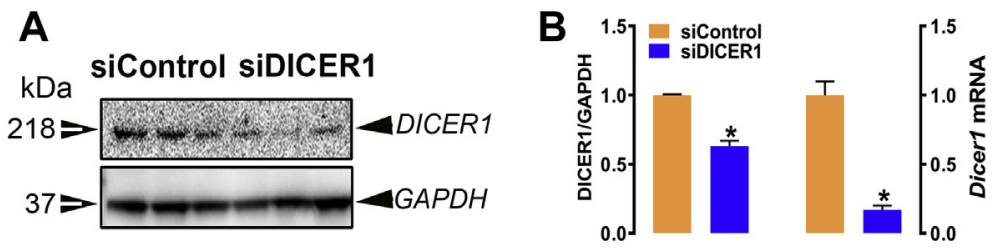

\section{C}
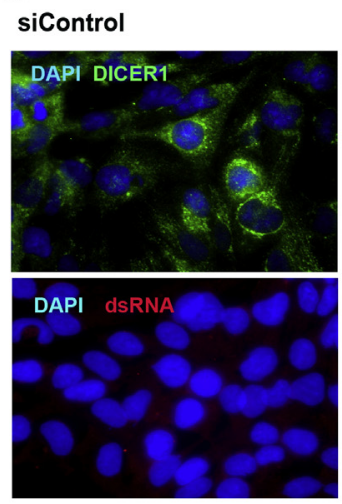

SIDICER1
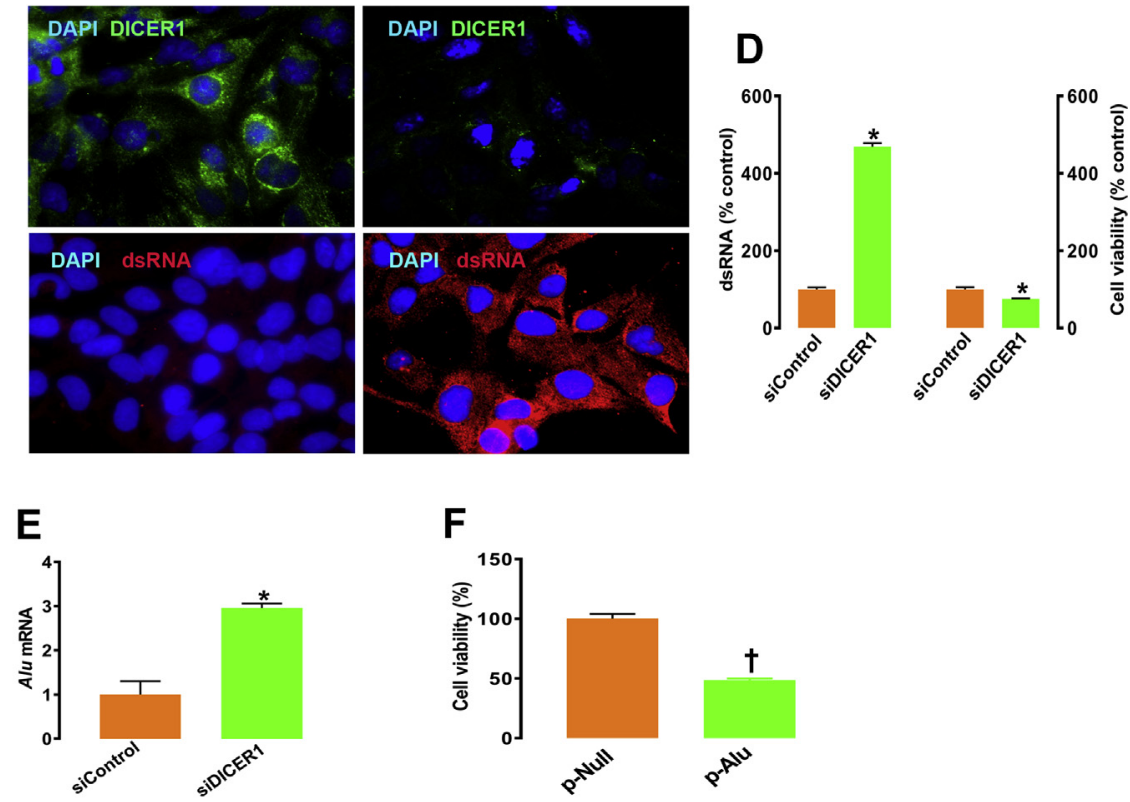

G
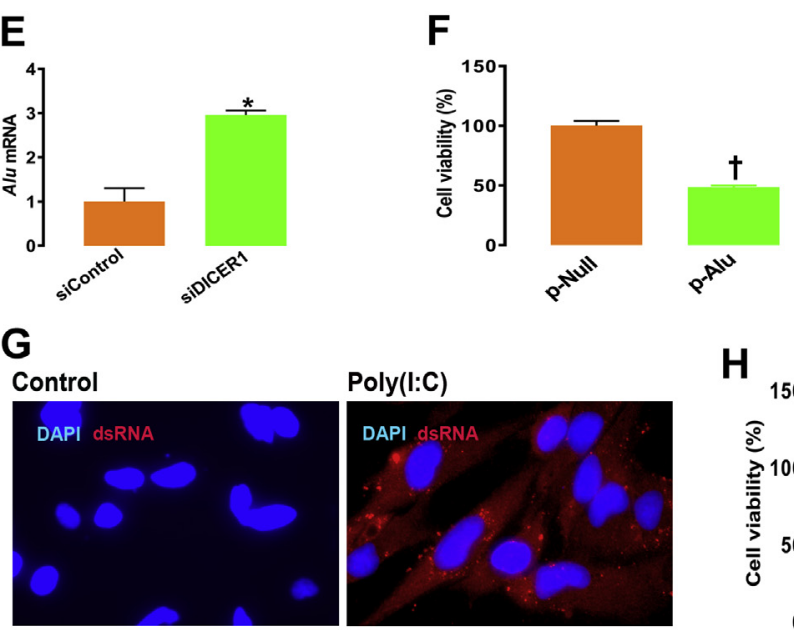

Figure 3 DICER1 knockdown induces dsRNA accumulation and reduces human fetal osteoblast (hFOB) cell viability. A-D: DICER1 deficit, mediated by siRNA $(\mathbf{A}-\mathbf{C})$, induces dsRNA accumulation (C and $\mathbf{D}$ ) and reduces hFOB cell viability (D). E and F: DICER1 knockdown up-regulates the expression of Alu repeat transcript (E), and hFOB cell viability is reduced by overexpression of Alu [plasmid (p-) Alu] relative to control vector ( $p$-null) $(\mathbf{F}) . \mathbf{G}$ and $\mathrm{H}$ : Administration of poly $(\mathrm{I}: \mathrm{C})$ reduces $\mathrm{hFOB}$ cell viability. Images are representative of three to four independent experiments. Data are expressed as means $\pm \operatorname{SEM}(\mathbf{B}, \mathbf{D}-\mathbf{F}$, and $\mathbf{H}) .{ }^{*} P<0.05$ versus siControl ( $t$-test); ${ }^{\dagger} P<0.05$ versus $p$-null ( $t$-test); ${ }^{\ddagger \ddagger} P<0.01$ versus control ( $t$-test). Original magnification, $\times 40$ (C and G). GAPDH, glyceraldehyde-3-phosphate dehydrogenase.

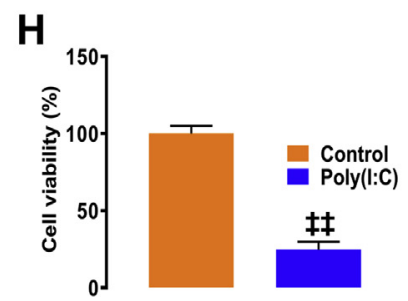




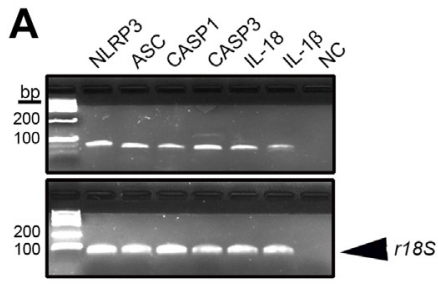

E

siControl
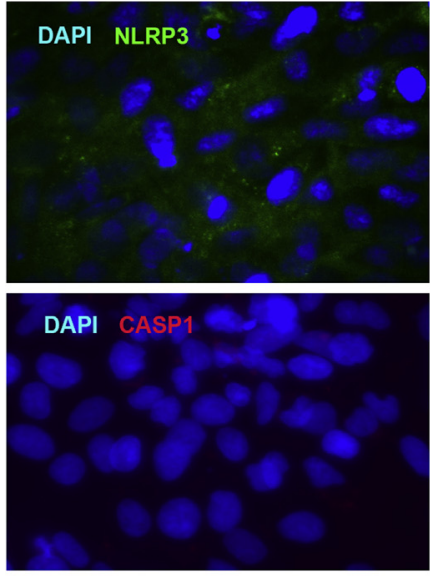
siDICER1
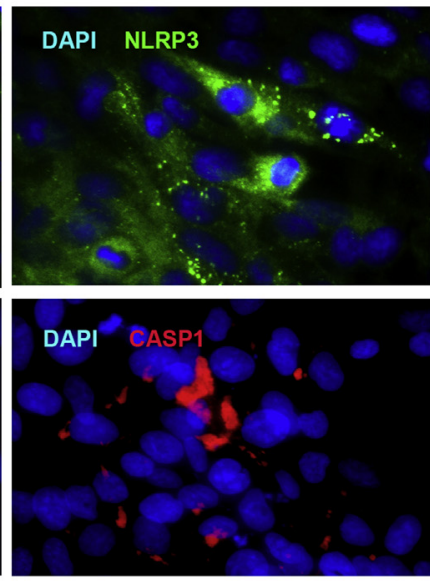

I

p-Null

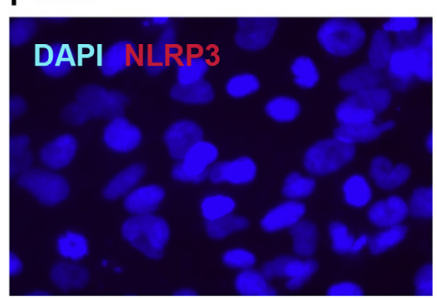

p-NLRP3
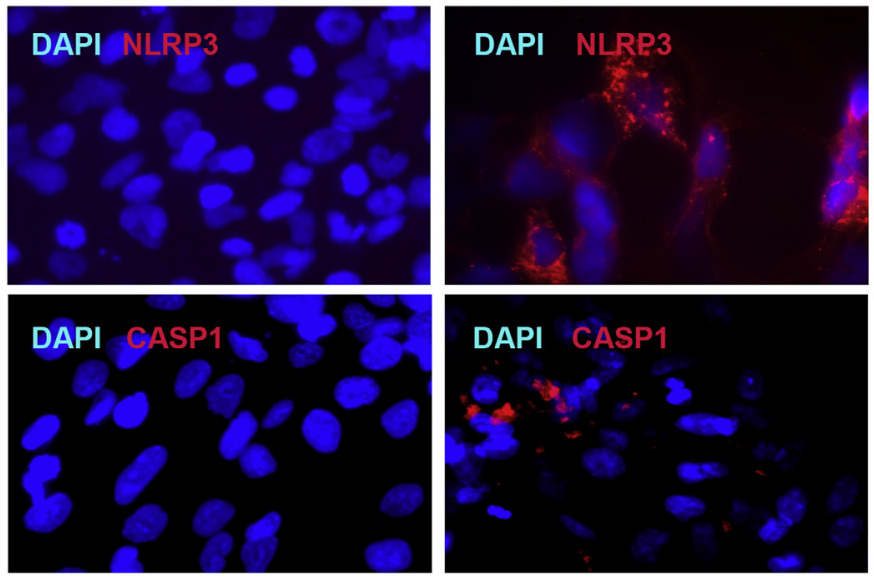
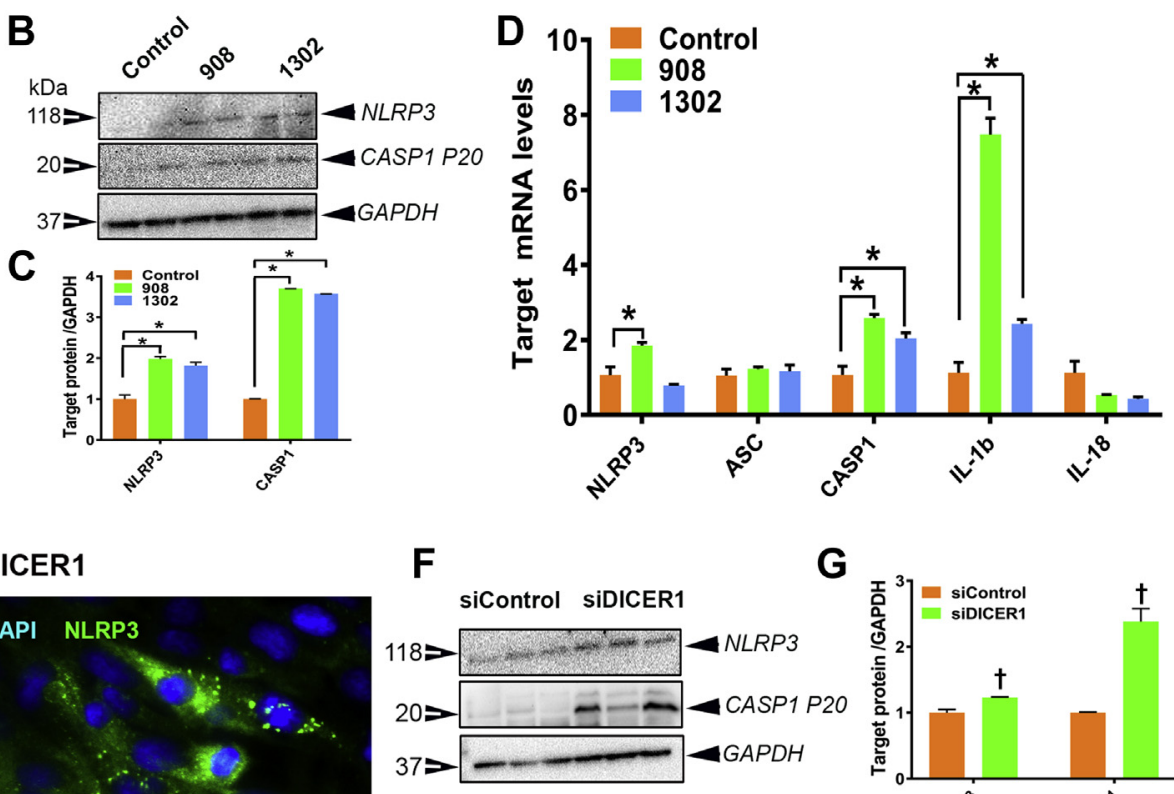

$\mathrm{H}$
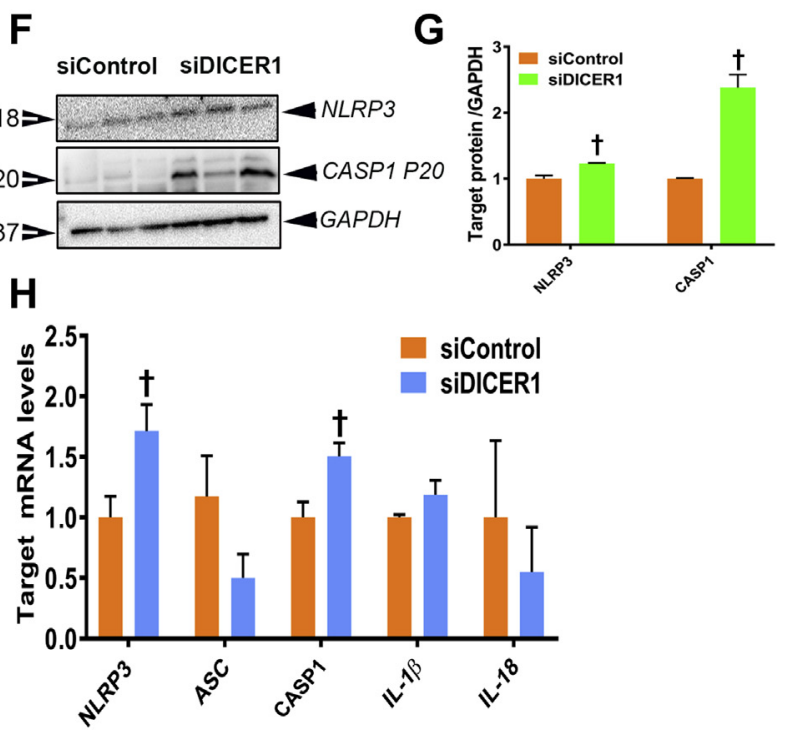

J

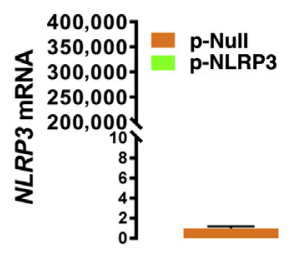

K
$\mathbf{L}$

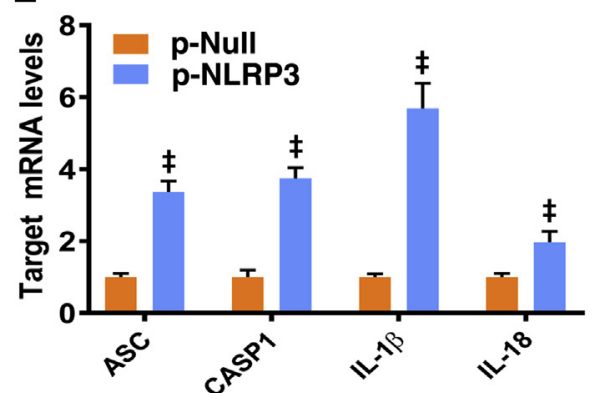

Figure 4 Staphylococcus infection and DICER1 dysregulation activate NACHT, LRR and PYD domains-containing protein (NLRP)3 inflammasome. A: NLRP3 inflammasome and its components are expressed in human fetal osteoblast (hFOB) cells. B-D: Infection with chicken bacterial chondronecrosis with osteomyelitis-Staphylococcus isolates (908 and 1302) activates NLRP3 inflammasome and its components (cleaved caspase 1-P20 and IL-1 3 ) in hF0B cells. E-H: Similarly, DICER1 knockdown activates NLRP3 inflammasome and its component. I-L: Transfection of plasmid coding for NLRP3 activates NLRP3 inflammasome and reduces $\mathrm{hFOB}$ cell viability. Images are representative of three to four independent experiments. Data are expressed as means \pm SEM (C, $\mathbf{D}$, $\mathbf{G}, \mathbf{H}$, and $\mathbf{J}-\mathbf{L}$ ). ${ }^{*} P<0.05$ versus control; ${ }^{\dagger} P<0.05$ versus siControl; ${ }^{\ddagger} P<0.05,{ }^{\ddagger \ddagger} P<0.01$, and ${ }^{\ddagger \ddagger \ddagger \ddagger} P<0.0001$ versus $p$-null (analysis of variance-StudentNewman-Keuls or $t$-test). Original magnification, $\times 40$ (E and I). ASC, apoptosis-associated speck-like protein; GAPDH, glyceraldehyde-3-phosphate dehydrogenase; NC, negative control; $\mathrm{p}$-, plasmid. 
A

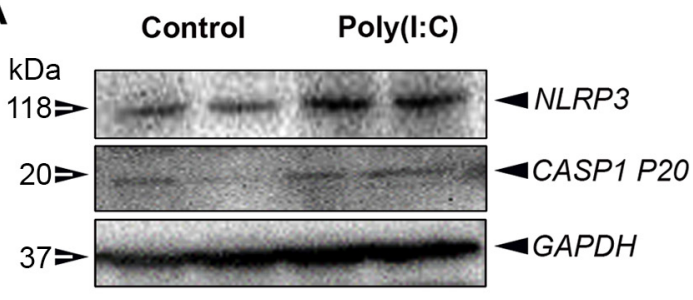

C

Control

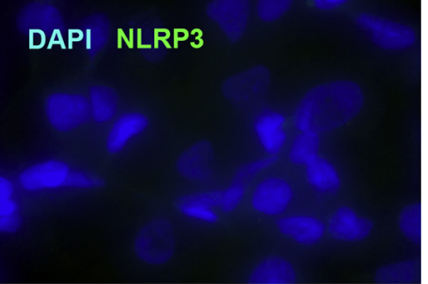

DAPI CASP1

E

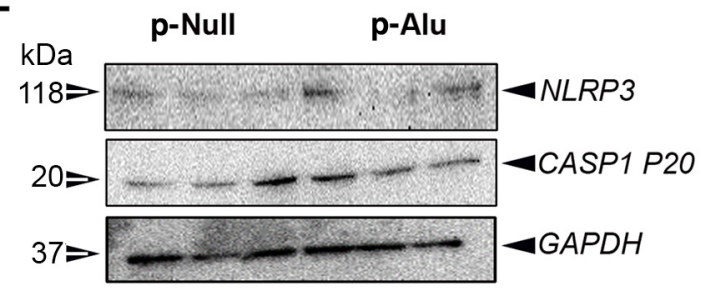

G

p-Null
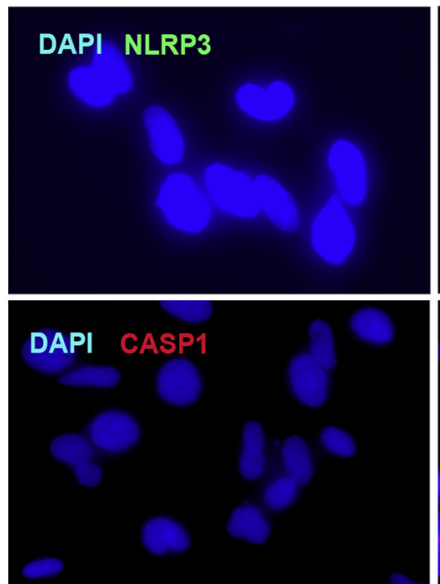

p-Alu

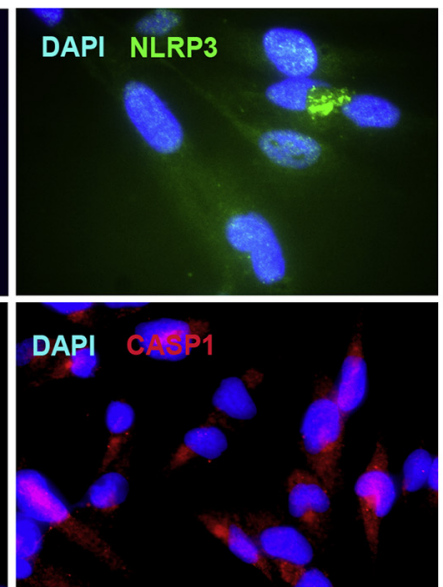

B

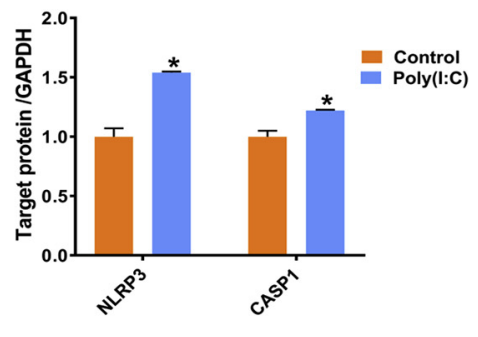

D

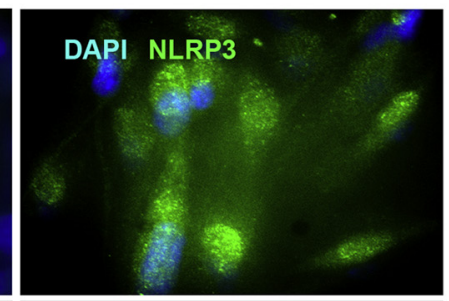

DAPI CASP1

$\mathbf{F}$

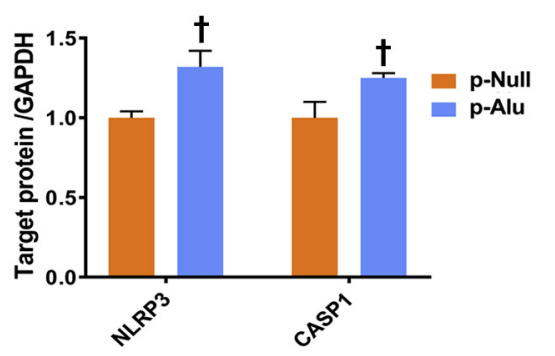

H

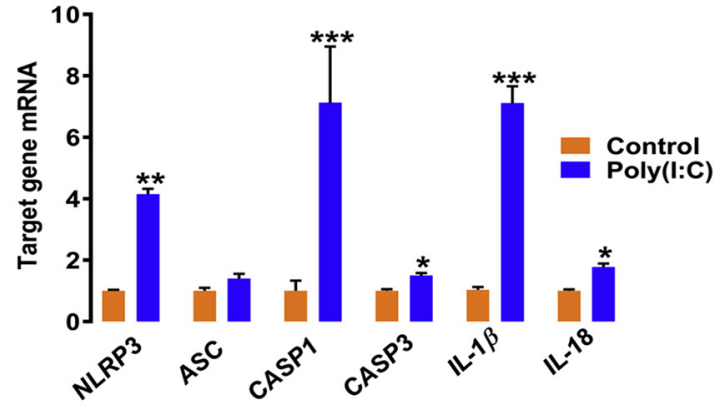

H

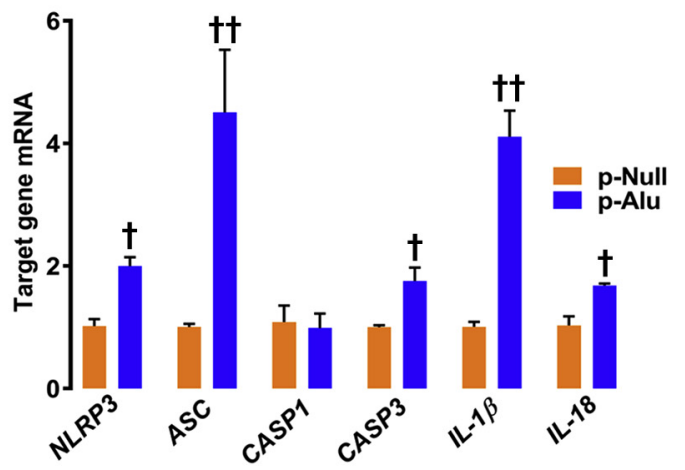

Figure 5 Administration of dsRNA activates NACHT, LRR and PYD domains-containing protein (NLRP)3 inflammasome. Administration of poly(I:C) (A-D) or overexpression of Alu $(\mathbf{E}-\mathbf{H})$ activates NLRP3 inflammasome and its component. Images are representative of three to four independent experiments. Values are expressed as means \pm SEM (B, D, F, and $\mathbf{H}) .{ }^{*} P<0.05,{ }^{* *} P<0.01$, and ${ }^{* * *} P<0.001$ versus control ( $t$-test); ${ }^{\dagger} P<0.05,{ }^{\dagger \dagger} P<0.01$ versus $p$-null $(t$-test). Original magnification, $\times \mathbf{4 0}(\mathbf{C}$ and $\mathbf{G})$. ASC, apoptosis-associated speck-like protein; GAPDH, glyceraldehyde-3-phosphate dehydrogenase; $p$-, plasmid. 


\section{A}
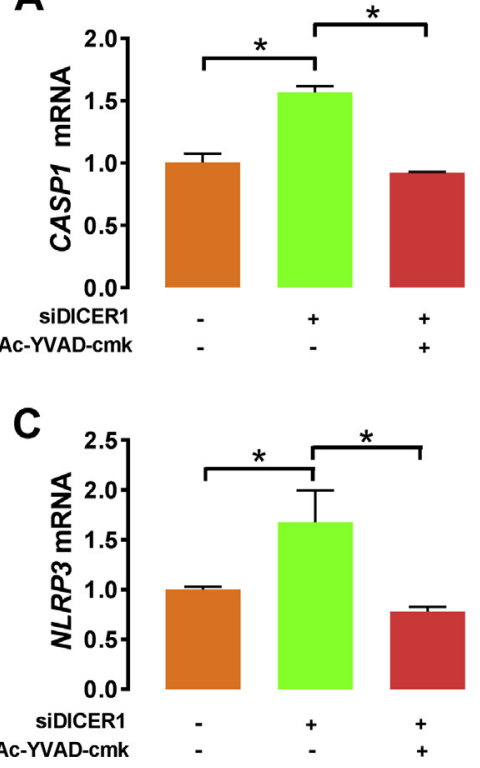

\section{B}
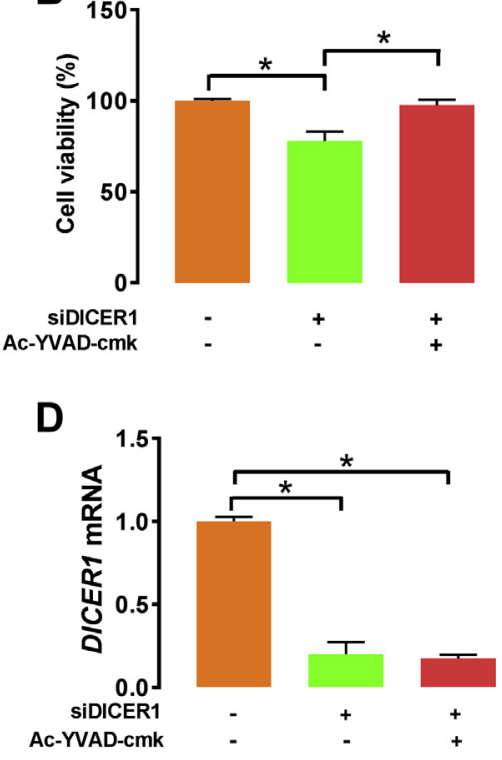

Figure 6 Inflammasome blockade protects human fetal osteoblast (hFOB) cells from DICER1 dysregulation/ dsRNA accumulation-induced cytotoxicity. Ac-YVAD-cmk, selective caspase 1 inhibitor (A), protects hFOB cells from DICER1 deficit-induced cell death (B). Ac-YVAD-cmk reduces NACHT, LRR and PYD domains-containing protein (NLRP)3 expression (C) but not that of DICER1 (D). Data are presented as means \pm SEM $(\mathbf{A}-\mathbf{D})$. ${ }^{*} P<0.05$.

\section{Staphylococcus Infection, DICER1 Knockdown, or dsRNA Administration Activates NLRP3 Inflammasome in Human Osteoblast Cells}

On the basis of a previously published study, ${ }^{21}$ it was hypothesized that dsRNA could activate NLRP3 inflammasome. First, it was determined that the components of NLRP3 inflammasome are expressed in hFOB cells (Figure 4A). Staphylococcus (908 and 1302) infection significantly increased the expression of NLRP3, the cleaved (active) caspase 1-P20, and IL-1 $\beta$ (Figure 4, B-D). Similarly, DICER1 knockdown activated NLRP3 inflammasome and increased the expression of its components (Figure 4, E-H, and Supplemental Figure S1). Overexpression of NLRP3 alone was sufficient to up-regulate the expression of caspase 1 and its downstream mediators (IL$1 \beta$, IL-18) and to reduce hFOB cell viability (Figure 4, I-L). Administration of poly(I:C) activated NLRP3 and increased the expression of caspase 1-P20, IL-1 $\beta$, and IL-18 (Figure 5, A-D). Overexpression of Alu repeat element also activates NLRP3 and increases the expression of its components (ASC and caspase 1-P20) as well as that of IL-1 $\beta$ and IL-18 (Figure 5, E-H).

\section{Blocking NLRP3 Component Rescues 0steoblast Cell Viability}

Caspase 1-inhibitor Ac-YVAD-cmk reduces CASP1 expression and completely prevents DICER 1 deficit/dsRNA accumulation-induced hFOB cell death (Figure 6, A and B). Similarly, Ac-YVAD-cmk prevents the activation of NLRP3 induced by DICER1 dysregulation (Figure 6C), but it did not elicit any changes to DICERI expression (Figure 6D).

\section{NLRP3 Inflammasome Is Activated in Bone of BCO Chicken and Humans with Osteomyelitis}

Next, it was tested whether human bone with osteomyelitis and chicken BCO bone, which exhibit loss of DICER1 and accumulation of dsRNA, also display evidence of NLRP3 inflammasome activation. Both NLRP3 mRNA abundance and protein levels were significantly increased in chicken BCO (Figure 7, A, C, and E) and human bone with osteomyelitis compared with their healthy counterparts (Figure 7, B, D, and F). Similarly, CASP1 and IL- $1 \beta$ mRNA as well as active cleaved caspase 1-P20 were markedly increased in human bone with osteomyelitis and in BCO chickens compared with their healthy counterparts (Figure 7). However, when compared with healthy subjects, the abundance of IL-18 mRNA was increased only in chicken BCO but not in human bone with osteomyelitis (Figure 7, E and F).

\section{Discussion}

Although it is well established that Staphylococcus infection is the major cause for osteomyelitis, nevertheless its etiology as well as its underlying mechanism are still not well defined. Herein, by using a human-relevant BCO animal model, ${ }^{17}$ our findings identified a novel pathophysiological pathway and elucidated a critical survival function for DICER1/dsRNA dysmetabolism in Staphylococcus infection-induced osteomyelitis pathogenesis.

The strengths of this experimental BCO model are that it triggers reproducible and spontaneous development of high lameness incidences without surgery or inoculation of exogenous pathogens or the need to develop metabolic engineering transgenesis and the accompanying lesions that resemble hematogenous staphylococcal osteomyelitis in 


\section{Chicken}

A

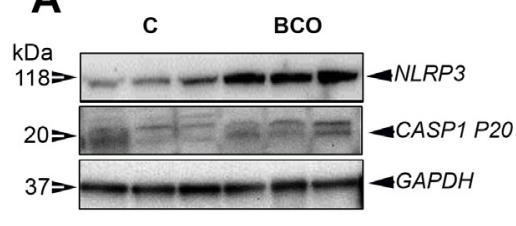

C

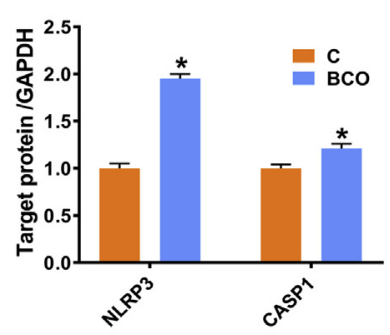

E

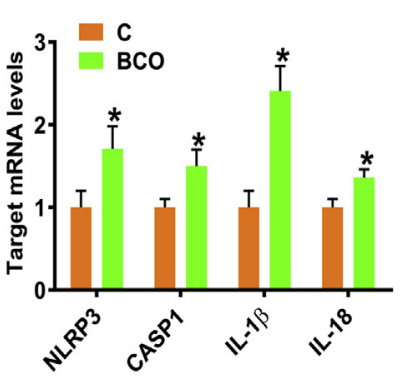

\section{Human}

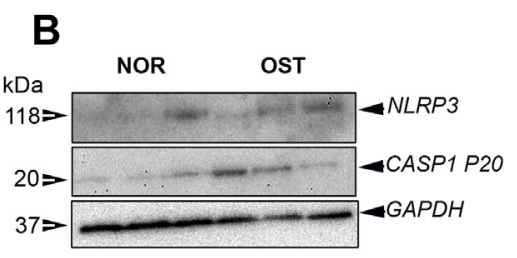

D

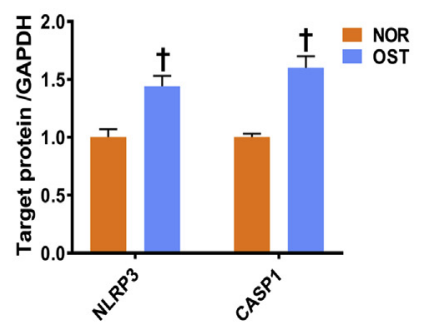

$\mathbf{F}$

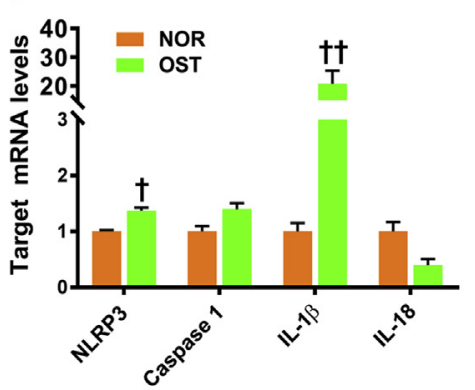

Figure 7 NACHT, LRR and PYD domains-containing protein (NLRP) 3 inflammasome activation in bone of bacterial chondronecrosis with osteomyelitis (BCO) chicken and human with osteomyelitis. The expression of NLRP3 inflammasome and its component is significantly elevated in the bone of $\mathrm{BCO}$ chicken $(\mathbf{A}-\mathbf{C})$ and human with osteomyelitis (OST; D-F) compared with healthy controls (CS). Data are expressed a means \pm SEM $(\mathbf{C}-\mathbf{F})$. ${ }^{*} P<0.05$ versus control ( $t$-test); ${ }^{\dagger} P<0.05,{ }^{\dagger \dagger} P<0.01$ versus normal (NOR) (t-test). GAPDH, glyceraldehyde-3phosphate dehydrogenase. growing children as well as in adult avascular femoral head necrosis. ${ }^{17,18,29}$ Because chickens are hyperglycemic and insulin resistant, ${ }^{30,31}$ this BCO model is also highly relevant for mechanistic understanding of osteomyelitis pathogenesis in susceptible human subjects.

DICER1 emerges as a multifaceted protein; and its dysregulation is increasingly recognized in several human diseases, including cancer, ${ }^{32}$ cardiovascular disease, ${ }^{33}$ and diabetes. $^{34}$ Recently, DICER1 has been reported to play a critical role in osteogenesis, ${ }^{35,36}$ and its dysregulation has been shown to alter cortical bone integrity and homeostasis. $^{37,38}$ As these effects of DICER1 are associated with RUNX2 $2^{36}$ and as RUNX2 was found to be involved in BCO pathogenesis, ${ }^{39}$ we hypothesized that DICER 1 might also be involved. The critical role of DICER 1 in mediating bone attrition was demonstrated by its expression deficit in tibia of BCO chicken and in human bone with osteomyelitis compared with the healthy controls as well as by rescuing hFOB osteoblast viability in culture.

The RNase III endonuclease, DICER1, cleaves 60- to 70nucleotide hairpin structured precursor miRNAs to yield miRNA or siRNA of defined length, typically approximately 22 nucleotides, that, together with argonaute proteins and associated factors, abrogates target mRNA by either degradation or translational inhibition. ${ }^{40}$

miRNAs have been extensively investigated in hostpathogen interactions of $>50$ different infections, including staphylococcal infection and osteomyeltis. ${ }^{41,42}$ However, DICER1 also processes long dsRNA, such as inverted repeat elements. ${ }^{20}$ Given the evidence that the IL-1 pathway is a downstream target for dsRNA, ${ }^{21}$ and the IL-1 pathway plays a pivotal role in the pathogenesis of human bone inflammation, including chronic recurrent multifocal osteomyelitis, ${ }^{43}$ we explored the concept that staphylococcal infection-induced DICER1 dysregulation might induce dsRNA accumulation. By using an anti-dsRNA antibody that binds long dsRNAs in a sequence-independent manner, we demonstrated that dsRNA levels were higher in BCO tibia and human bone with osteomyelitis compared with their healthy counterparts. Similarly, dsRNA levels were also induced by DICER1 knockdown or Staphylococcus infection in human osteoblasts in culture. This accumulated dsRNA after DICER1 depletion, bacterial infection, administration of dsRNA analogue, or a plasmid encoding for transposable $A l u$ repeat element induces osteoblast cell death. Although the origin and the identity of these 
endogenously accumulated cytotoxic dsRNAs are not known at this time and merit further in-depth investigation, they might derive from overlapping convergent transcription of distinct protein coding genes, ${ }^{44}$ natural antisense noncoding RNA, ${ }^{45}$ or inverted repeat transcription. ${ }^{46}$ It would be crucial to determine the sequences and the identities of these cytotoxic dsRNAs by immunoprecipitation and amplification-based analysis and see whether they are precursors for miRNA or a new class of noncoding RNA species.

Although the bone is a complex organ with exceptional immune privilege, ${ }^{47}$ bacterial insults can trigger the innate immune NLRP3 sensors and result in bone inflammation and attrition. ${ }^{48}$ To test this possibility and to define the downstream mediators used by DICER1/dsRNA dysregulation to induce bone degeneration, we showed that, in agreement with a previous study, ${ }^{49}$ the components of NLRP3 inflammasome are expressed in osteoblasts. It was further shown that this inflammasome is activated by Staphylococcus infection, DICER1 knockdown, or dsRNA administration. Similarly, NLRP3 inflammasome is activated in BCO tibia and in human bone with osteomyelitis compared with healthy controls. Blocking caspase 1 activation completely rescued osteoblast cell viability. The reduced expression of NLRP3 by Ac-YVAD-cmk (Figure 6C) suggests a potential negative feedback loop between caspase 1 and NLRP3 inflammasome. Moreover, there are several inflammasome families that have the ability to activate caspase 1, including NLR (NLRP1, NLRP3, NLRC4, NLRP6, and NLRP12), ALR (AIM2), and Pyrin. ${ }^{50}$ Further work should determine whether DICER1/dsRNA dysregulation triggers the activation of other inflammasomes. The active caspase 1 subunits can proteolytically process IL-1 $\beta$ and IL-18, and this study demonstrates that these cytokines are downstream of caspase 1 activation. However, further studies are warranted to determine whether the osteoblast cell death is mediated by apoptosis, pyroptosis, and/or necrosis.

Although the upstream regulators of DICER 1 deficit, dsRNA identity, mechanisms of dsRNA-NLRP3 interaction, as well as the forms of caspase 1-dependent osteoblast cell death await clarification, the BCO model implicates DICER1/dsRNA dysmetabolism in the pathogenesis of osteomyelitis and may be useful as a platform for validating potential therapies.

\section{Acknowledgments}

We thank Dr. Charles O'Brien (University of Arkansas for Medical Sciences, Little Rock, AR) for Ob-6 cells; and Drs. Ronald N. Germain and Naeha Subramanian (Institute for Systems Biology, Seattle, WA) for plasmid NLRP3.

S.D. designed research; A.A., D.R., and R.W. performed bacterial chondronecrosis with osteomyelitis experiments and provided tissue and bacterial samples; S.H. and J.P. provided human specimens; E.G. and J.F. performed molecular and biochemical analyses; S.D., J.K., J.G., and A.R. provided reagents; M.S. provided the LAC and UAMS1 strains for the revision; E.G. analyzed data; S.D. wrote the manuscript; E.G., J.F., A.D., A.A., S.H., J.P., J.K., J.G., A.R., R.W., D.R., and S.D. reviewed the manuscript.

\section{Supplemental Data}

Supplemental material for this article can be found at http://doi.org/10.1016/j.ajpath.2019.06.013.

\section{References}

1. Game F: Management of osteomyelitis of the foot in diabetes mellitus. Nat Rev Endocrinol 2010, 6:43-47

2. Lowy FD: Staphylococcus aureus infections. N Engl J Med 1998, 339:520-532

3. Weigel LM, Clewell DB, Gill SR, Clark NC, McDougal LK, Flannagan SE, Kolonay JF, Shetty J, Killgore GE, Tenover FC: Genetic analysis of a high-level vancomycin-resistant isolate of Staphylococcus aureus. Science 2003, 302:1569-1571

4. Oliveira DC, Tomasz A, de Lencastre H: Secrets of success of a human pathogen: molecular evolution of pandemic clones of methicillin-resistant Staphylococcus aureus. Lancet Infect Dis 2002, 2:180-189

5. Chang S, Sievert DM, Hageman JC, Boulton ML, Tenover FC, Downes FP, Shah S, Rudrik JT, Pupp GR, Brown WJ, Cardo D, Fridkin SK; Vancomycin-Resistant Staphylococcus aureus Investigative Team: Infection with vancomycin-resistant Staphylococcus aureus containing the vanA resistance gene. N Engl J Med 2003, 348 : $1342-1347$

6. Brady RA, Leid JG, Calhoun JH, Costerton JW, Shirtliff ME: Osteomyelitis and the role of biofilms in chronic infection. FEMS Immunol Med Microbiol 2008, 52:13-22

7. Beck-Broichsitter BE, Smeets R, Heiland M: Current concepts in pathogenesis of acute and chronic osteomyelitis. Curr Opin Infect Dis 2015, 28:240-245

8. Kremers HM, Nwojo ME, Ransom JE, Wood-Wentz CM, Melton LJ 3rd, Huddleston PM 3rd: Trends in the epidemiology of osteomyelitis: a population-based study, 1969 to 2009. J Bone Joint Surg Am 2015, 97:837-845

9. Lew DP, Waldvogel FA: Osteomyelitis. Lancet 2004, 364:369-379

10. Josse J, Velard F, Gangloff SC: Staphylococcus aureus vs. osteoblast: relationship and consequences in osteomyelitis. Front Cell Infect Microbiol 2015, 5:85

11. Norden CW: Experimental osteomyelitis, I: a description of the model. J Infect Dis 1970, 122:410-418

12. Rissing JP, Buxton TB, Weinstein RS, Shockley RK: Model of experimental chronic osteomyelitis in rats. Infect Immun 1985, 47: $581-586$

13. Chadha HS, Fitzgerald RH Jr, Wiater P, Sud S, Nasser S, Wooley PH: Experimental acute hematogenous osteomyelitis in mice, I: histopathological and immunological findings. J Orthop Res 1999, 17: 376-381

14. Garvin KL, Miyano JA, Robinson D, Giger D, Novak J, Radio S: Polylactide/polyglycolide antibiotic implants in the treatment of osteomyelitis: a canine model. J Bone Joint Surg Am 1994, 76: $1500-1506$

15. Kaarsemaker S, Walenkamp GH, vd Bogaard AE: New model for chronic osteomyelitis with Staphylococcus aureus in sheep. Clin Orthop Relat Res 1997, 339:246-252 
16. Ferguson PJ, Bing $\mathrm{X}$, Vasef MA, Ochoa LA, Mahgoub A, Waldschmidt TJ, Tygrett LT, Schlueter AJ, El-Shanti H: A missense mutation in pstpip2 is associated with the murine autoinflammatory disorder chronic multifocal osteomyelitis. Bone 2006, 38:41-47

17. Wideman RF, Prisby RD: Bone circulatory disturbances in the development of spontaneous bacterial chondronecrosis with osteomyelitis: a translational model for the pathogenesis of femoral head necrosis. Front Endocrinol 2012, 3:183

18. Wideman RF Jr, Hamal KR, Stark JM, Blankenship J, Lester H, Mitchell KN, Lorenzoni G, Pevzner I: A wire-flooring model for inducing lameness in broilers: evaluation of probiotics as a prophylactic treatment. Poult Sci 2012, 91:870-883

19. Gurung P, Burton A, Kanneganti TD: NLRP3 inflammasome plays a redundant role with caspase 8 to promote IL-1beta-mediated osteomyelitis. Proc Natl Acad Sci U S A 2016, 113:4452-4457

20. Kaneko H, Dridi S, Tarallo V, Gelfand BD, Fowler BJ, Cho WG, et al: DICER1 deficit induces Alu RNA toxicity in age-related macular degeneration. Nature 2011, 471:325-330

21. Tarallo V, Hirano Y, Gelfand BD, Dridi S, Kerur N, Kim Y, Cho WG, Kaneko H, Fowler BJ, Bogdanovich S, Albuquerque RJ, Hauswirth WW, Chiodo VA, Kugel JF, Goodrich JA, Ponicsan SL, Chaudhuri G, Murphy MP, Dunaief JL, Ambati BK, Ogura Y, Yoo JW, Lee DK, Provost P, Hinton DR, Nunez G, Baffi JZ, Kleinman ME, Ambati J: DICER1 loss and Alu RNA induce agerelated macular degeneration via the NLRP3 inflammasome and MyD88. Cell 2012, 149:847-859

22. Committee for the Update of the Guide for the Care and Use of Laboratory AnimalsNational Research Council: Guide for the Care and Use of Laboratory Animals: Eighth Edition. Washington, DC, National Academies Press, 2011

23. Dridi S, Hirano Y, Tarallo V, Kim Y, Fowler BJ, Ambati BK, Bogdanovich S, Chiodo VA, Hauswirth WW, Kugel JF, Goodrich JA, Ponicsan SL, Hinton DR, Kleinman ME, Baffi JZ, Gelfand BD, Ambati J: ERK1/2 activation is a therapeutic target in age-related macular degeneration. Proc Natl Acad Sci U S A 2012, 109:13781-13786

24. Subramanian N, Natarajan K, Clatworthy MR, Wang Z, Germain RN: The adaptor MAVS promotes NLRP3 mitochondrial localization and inflammasome activation. Cell 2013, 153:348-361

25. Al-Rubaye AA, Couger MB, Ojha S, Pummill JF, Koon JA 2nd, Wideman RF Jr, Rhoads DD: Genome analysis of Staphylococcus agnetis, an agent of lameness in broiler chickens. PLoS One 2015, 10: $\mathrm{e} 0143336$

26. Carter LE, Kilroy G, Gimble JM, Floyd ZE: An improved method for isolation of RNA from bone. BMC Biotechnol 2012, 12:5

27. Schmittgen TD, Livak KJ: Analyzing real-time PCR data by the comparative C(T) method. Nat Protoc 2008, 3:1101-1108

28. Wijesurendra DS, Chamings AN, Bushell RN, Rourke DO, Stevenson M, Marenda MS, Noormohammadi AH, Stent A: Pathological and microbiological investigations into cases of bacterial chondronecrosis and osteomyelitis in broiler poultry. Avian Pathol 2017, 46:683-694

29. Ren W, Shen S, Sun Z, Shu P, Shen X, Bu C, Ai F, Zhang X, Tang A, Tian L, Li G, Li X, Ma J: Jak-STAT3 pathway triggers DICER1 for proteasomal degradation by ubiquitin ligase complex of CUL4A(DCAF1) to promote colon cancer development. Cancer Lett 2016, 375 : 209-220

30. Seki Y, Sato K, Kono T, Abe H, Akiba Y: Broiler chickens (Ross strain) lack insulin-responsive glucose transporter GLUT4 and have GLUT8 cDNA. Gen Comp Endocrinol 2003, 133:80-87

31. Simon J, Freychet P, Rosselin G: A study of insulin binding sites in the chicken tissues. Diabetologia 1977, 13:219-228

32. Hata A, Kashima R: Dysregulation of microRNA biogenesis machinery in cancer. Crit Rev Biochem Mol Biol 2016, 51:121-134
33. Chen J-F, Murchison EP, Tang R, Callis TE, Tatsuguchi M, Deng Z, Rojas M, Hammond SM, Schneider MD, Selzman CH, Meissner G, Patterson C, Hannon GJ, Wang D-Z: Targeted deletion of Dicer in the heart leads to dilated cardiomyopathy and heart failure. Proc Natl Acad Sci U S A 2008, 105:2111-2116

34. Elgheznawy A, Shi L, Hu J, Wittig I, Laban H, Pircher J, Mann A, Provost P, Randriamboavonjy V, Fleming I: Dicer cleavage by calpain determines platelet microRNA levels and function in diabetes. Circ Res 2015, 117:157

35. Zhou J, Hu Y, Chen Y, Yang L, Song J, Tang Y, Deng F, Zheng L: Dicer-dependent pathway contribute to the osteogenesis mediated by regulation of Runx2. Am J Transl Res 2016, 8:5354-5369

36. Zheng L, Tu Q, Meng S, Zhang L, Yu L, Song J, Hu Y, Sui L, Zhang J, Dard M, Cheng J, Murray D, Tang Y, Lian JB, Stein GS, Chen J: Runx2/DICER/miRNA pathway in regulating osteogenesis. J Cell Physiol 2017, 232:182-191

37. Bendre A, Moritz N, Vaananen V, Maatta JA: Dicer1 ablation in osterix positive bone forming cells affects cortical bone homeostasis. Bone 2018, 106:139-147

38. Liu P, Baumgart M, Groth M, Wittmann J, Jack HM, Platzer M, Tuckermann JP, Baschant U: Dicer ablation in osteoblasts by Runx2 driven cre-loxP recombination affects bone integrity, but not glucocorticoid-induced suppression of bone formation. Sci Rep 2016, 6:32112

39. Paludo E, Ibelli AMG, Peixoto JO, Tavernari FC, Lima-Rosa CAV, Pandolfi JRC, Ledur MC: The involvement of RUNX2 and SPARC genes in the bacterial chondronecrosis with osteomyelitis in broilers. Animal 2017, 11:1063-1070

40. Bartel DP: MicroRNAs: target recognition and regulatory functions. Cell 2009, 136:215-233

41. Jin T, Lu Y, He QX, Wang H, Li BF, Zhu LY, Xu QY: The role of MicroRNA, miR-24, and its target CHI3L1 in osteomyelitis caused by Staphylococcus aureus. J Cell Biochem 2015, 116:2804-2813

42. Liu J, Li D, Sun X, Wang Y, Xiao Q, Chen A: Icariine restores LPSinduced bone loss by downregulating miR-34c level. Inflammation 2016, 39:1764-1770

43. Cassel SL, Janczy JR, Bing X, Wilson SP, Olivier AK, Otero JE, Iwakura Y, Shayakhmetov DM, Bassuk AG, Abu-Amer Y, Brogden KA, Burns TL, Sutterwala FS, Ferguson PJ: Inflammasome-independent IL-1beta mediates autoinflammatory disease in Pstpip2-deficient mice. Proc Natl Acad Sci U S A 2014, 111: 1072-1077

44. Gullerova M, Proudfoot NJ: Cohesin complex promotes transcriptional termination between convergent genes in S. pombe. Cell 2008, 132:983-995

45. Faghihi MA, Wahlestedt C: Regulatory roles of natural antisense transcripts. Nat Rev Mol Cell Biol 2009, 10:637-643

46. White E, Schlackow M, Kamieniarz-Gdula K, Proudfoot NJ, Gullerova M: Human nuclear Dicer restricts the deleterious accumulation of endogenous double-stranded RNA. Nat Struct Mol Biol 2014, 21:552-559

47. Lorenzo J, Horowitz M, Choi Y: Osteoimmunology: interactions of the bone and immune system. Endocr Rev 2008, 29:403-440

48. Sha W, Mitoma H, Hanabuchi S, Bao M, Weng L, Sugimoto N, Liu Y, Zhang Z, Zhong J, Sun B, Liu YJ: Human NLRP3 inflammasome senses multiple types of bacterial RNAs. Proc Natl Acad Sci U S A 2014, 111:16059-16064

49. McCall SH, Sahraei M, Young AB, Worley CS, Duncan JA, Ting JP, Marriott I: Osteoblasts express NLRP3, a nucleotide-binding domain and leucine-rich repeat region containing receptor implicated in bacterially induced cell death. J Bone Miner Res 2008, 23:30-40

50. Sharma D, Kanneganti TD: The cell biology of inflammasomes: mechanisms of inflammasome activation and regulation. J Cell Biol 2016, 213:617-629 